Expl Cell Biol. 1977;45:121

\title{
To Our Readers
}

With this issue Experimental Cell Biology is expanding its coverage. In addition to the three sections which existed so far (Pathology, Microbiology, Immunology), we are introducing a fourth one, to be devoted to developmental cell biology (Differentiation). This step is a logical continuation of our efforts to cover more aspects of experimental cell biology than the earlier title of the journal has implied.

The developmental, or morphogenetic, aspects of cell biology, often referred to as the domain of cell differentiation, are today attracting much attention and are under intensive study by many investigators in many institutions. These studies are making significant contributions to the understanding of biological phenomena on the cellular (and subcellular) level. It seems therefore appropriate that we open our columns for this branch of cell biology and provide a new meeting ground for the growing number of scientists who are interested, and/or work actively in this field. The new section (Differentiation) will publish papers on problems of short-term and longterm changes in the structure and function of cells within their life span, such as temporal changes in enzyme activity or permanent structural changes in the course of embryonic and postem-bryonic development, regeneration, etc., as well as papers on the genetic and environmental mechanisms which bring about and regulate these changes, both normal and pathologic ones, including oncogenic transformations.

The editor of the new section is Prof. Alexander Wolsky (Department of Radiology, New York University Medical Center - Bellevue, 550 First Avenue, New York, NY 10016) and manuscripts considered to come under the heading of developmental cell biology (Differentiation), as defined above, should be sent to him. The section also has its own group of co-editors who will participate in the evaluation and selection of the papers to be published. The editors of Experimental Cell Biology sincerely hope that interested scientists will take advantage of the extended coverage of the journal and will participate in the new effort, both as readers and as contributors, to make it a success. 